EDITORIAL

\title{
Immigrants, Descendants and the Risk of Coronary Heart Disease
}

\author{
Antonio Carlos Palandri Chagas ${ }^{1,2}{ }^{\circledR}$ and João Fernando Monteiro Ferreira ${ }^{1,2}$ \\ Faculdade de Medicina do Centro Universitário do ABC, 'São Paulo, SP - Brazil \\ Instituto do Coração da Faculdade de Medicina da Universidade de São Paulo, ${ }^{2}$ São Paulo, SP - Brazil \\ Editorial referring to the article: Ischemic Heart Disease in German Immigrants and Their Descendants in a Region of Southern Brazil: \\ A Comparison of Initial Symptoms Reported between Two Generations
}

Cardiovascular disease remains the leading cause of death worldwide and in all regions of Brazil. ${ }^{1}$ Racial, cultural, and environmental factors contribute to different prevalence rates of risk factors and presentations of the disease. Differences have been found between Whites, Hispanics, Asians, and Afro-descendants, and even within each race, due to migratory movements. ${ }^{2,3}$

Changes in the socio-demographic profile of migrant populations have resulted in health transitions, considering the country of origin (some of them with a high risk for certain diseases) and changes in lifestyle and diet in the new country. Several studies have found a significant linear relationship between migration and acculturation, alcohol consumption, lipid profile, blood pressure, body mass index and physical activity. ${ }^{4-6}$

Brazil is one of the countries with the greatest cultural diversity that is explained by the origin of its population. Brazil has absorbed numerous nationalities and cultures throughout its historical formation resulting from intense immigration, especially at the turn of the 19th century and in the 1920s. ${ }^{7}$

For example, new geographic and cultural contexts due to the immigration from Germany to Brazil have changed the disease profile of these immigrants and their descendants. The study "Ischemic Heart Disease in German Immigrants and Their Descendants in a Region of Southern Brazil: A Comparison of Initial Symptoms Reported between Two Generations" by Zimmermann et al., ${ }^{8}$ published in this issue compared age at diagnosis and manifestations of ischemic heart disease (IHD)

\section{Keywords}

Atherosclerosis; Coronary Artery Disease; Imigrants and Descendants; Risk Factors; Epidemiology. between German immigrants and their first-generation descendants through the review of hospital records in the city of Blumenau, Brazil. The authors found that at the time of the first diagnosis of IHD, the mean age of participants born in Germany was significantly higher than the group of descendants and concluded that the earlier disease onset may be partly due to changes in the lifestyle of their children, including changing in eating habits characterized by high consumption of saturated fats.

Another Brazilian study also assessed the differences in the presentation of IHD between immigrants and their descendants. Amato et al. ${ }^{9}$ carried out a retrospective analysis of the clinical manifestations of coronary artery disease and the prevalence of risk factors, comparing 128 Japanese immigrants (Japanese group) with 304 Japanese descendants (Nisei group). The authors found that, despite a similar clinical presentation, the onset of coronary heart disease was nearly 12 years earlier in the Nisei group (mean $=53$ years) compared to the Japanese group $($ mean $=65$ years $)(P<0.001)$.

Interestingly, these studies did not find differences regarding risk factors, LDL levels or clinical and angiographic manifestations of the disease between immigrants and their descendants. Maybe, this can be explained by the retrospective, cross-sectional nature of the studies that evaluated initial manifestations of coronary heart disease. Even so, it may be assumed that Brazilian descendants were exposed earlier and perhaps more intensely to risk factors for IHD. To confirm this possibility, prospective cohort studies would be interesting, especially if including, in addition to body mass index, waist circumference and blood pressure measurements, laboratory tests, validated questionnaires on quality of life, and assessment of physical activity

Mailing Address: Antonio Carlos Palandri Chagas

Rua Manoel Coelho, 909. Postal Code: 09510-112, S. Caetano do Sul, SP - Brazil.

E-mail: chagas@fmabc.br 
level and eating habits, to confirm whether the earlier manifestation of IHD is associated also with an earlier onset of risk factors like diabetes, hypertension and dyslipidemia. Healthy habits combined with a regular diet are fundamental for an adequate control of risk factors to prevent premature occurrence of cardiovascular disease.

\section{References}

1. Sistema Único de Saúde (SUS). Departamento de Informática do SUS. [Internet] [Citado em 2021 nov 01] Disponível em: datasus. saúde.gov.br

2. Heart Disease and Stroke Statistics-2020 Update. Circulation. 2020;141:e139-e596).

3. Virani SS, Alonso A, Benjamin EJ, Bittencourt MS, Callaway CW, Carson $\mathrm{AP}$, et al. Health transition and immigration: a new challenge for Public Health. Ann Ig. Sep-Oct 2015;27(5):726-36.

4. Alkerwi A, Sauvageot N, Pagny S. Acculturation, immigration status and cardiovascular risk factors among Portuguese immigrants to Luxembourg: findings from ORISCAV-LUX study. BMC Public Health. 2012 Oct 11;12:864. doi:10.1186/1471-2458-12-864.

5. Rosentha T. Immigration and Acculturation: Impact on Health and WellBeing of Immigrants. Curr Hypertens Rep. 2018 Jul 3;20(8):70.

6. Lizarzaburu JL, Palenkas LA. Immigration, acculturation, and risk factors for obesity and cardiovascular disease: a comparison between Latinos of Peruvian descent in Peru and in the United States. Ethn Dis ( Summer )2002;12(3):342-52.

7. Brasil: 500 anos de povoamento / IBGE, Centro de Documentação e Disseminação de Informações. - Rio de Janeiro; 2007.

8. ZimmermannSL, Moretti MA, Vianna CV, Mansur AP, StarkeS, Cesar LAM Ischemic Heart Disease in German Immigrants and Their Descendants in a Region of Southern Brazil: A Comparison of Initial Symptoms Reported between Two Generations. Int J Cardiovasc Sci. 2022; 35(1):48-55.

9. Manifestação Clínica da doença coronariana e fatores de risco em imigrantes japoneses e seus descendentes em São Paulo. Amato RV, César LA, Mansur AP, Hueb WA, Martins JR, Vianna CB, et al. Coronary heart disease clinical manifestation and risk factors in Japanese immigrants and their descendents in the city of São Paulo. Arq Bras Cardiol. 2003;81(3):229-8 